\title{
Genetic characterisation of intestinal spirochaetes and their association with disease
}

\author{
J. I. LEE and D. J. HAMPSON* \\ School of Veterinary Studies, Murdoch University, Murdoch, Western Australia 6150, Australia
}

\begin{abstract}
Summary. Multilocus enzyme electrophoresis was used to assess genetic relationships amongst 175 isolates of anaerobic intestinal spirochaetes, including 72 isolates from individuals living in different parts of the world, 102 from pigs and one from a dog. Amongst porcine isolates belonging to the genus Serpulina, a possible new species was identified. All but one of the isolates from man were clustered with the canine isolate and 59 porcine isolates in a distinct group that we have previously called "Anguillina coli". The human and animal spirochaetes in this group had four-to-six axial flagella and most were recovered from individuals with diarrhoea. They included a strain of the so-called "Serpulina jonesii", that was not a true serpulina. These 71 human isolates were distributed into 44 electrophoretic types and had a mean genetic diversity of $0 \cdot 32$. These were further divided into 26 clonal groups. Three of these clones also contained porcine isolates, one of which was strain $\mathrm{P} 43 / 6 / 78$, the agent of porcine intestinal spirochaetosis. Four of the clones contained human isolates from different sources. One included isolates from Western Australian Aboriginal children and from Italian adults, and the other three contained isolates from Western Australian Aboriginal children and from homosexual males in Sydney, New South Wales. There were no known connections between these human populations. The other spirochaete of human origin was Brachyspira aalborgi, which was distinct from isolates in the genera Serpulina and "Anguillina". Both B. aalborgi and "A. coli" have been associated with human cases of intestinal spirochaetosis. Others have questioned the clinical significance of colonisation by $B$. aalborgi, but we suggest that isolates of " $A$. coli" may be the cause of some clinical cases of intestinal spirochaetosis.
\end{abstract}

\section{Introduction}

Weakly $\beta$-haemolytic anaerobic spirochaetes commonly colonise the large intestines of Gulf Arabs, ${ }^{1}$ Australian Aborigines, ${ }^{2}$ Africans, ${ }^{3}$ Indians, ${ }^{4}$ AIDS patients $^{5}$ and homosexual males in western societies. ${ }^{6-8}$ Other people in western societies are rarely colonised, ${ }^{2,9}$ and the reason for this is not understood. We have examined previously certain of these spirochaetes and found that they resemble a group of weakly $\beta$ haemolytic spirochaetes that are thought to cause "intestinal spirochaetosis" in pigs. ${ }^{10-13}$ These porcine intestinal spirochaetes have been called "Anguillina coli" ${ }^{11}$ and are distinct from porcine isolates of the genus Serpulina. The latter includes the strongly $\beta$ haemolytic pathogenic species $S$. hyodysenteriae, the aetiological agent of swine dysentery, ${ }^{14,15}$ the weakly $\beta$-haemolytic non-pathogenic species $S$. innocens, ${ }^{16}$ and the recently described species " $S$. intermedius". ${ }^{11}$ An isolate from a patient with diarrhoea has also been

Received 21 Oct. 1993; accepted 25 Nov. 1993.

* Correspondence should be sent to Dr D. J. Hampson. lodged recently with the American Type Culture Collection under the name "Serpulina jonesii" (ATCC number 49776).

In man, the consequences of colonisation by intestinal spirochaetes are unclear. Where there is heavy colonisation with end-on attachment of spirochaetes to the epithelium of the colon and rectum, the condition has been called "intestinal spirochaetosis". ${ }^{17,18}$ Some investigators believe that the bacteria can be responsible for various gastrointestinal disturbances, especially long-standing diarrhoea and rectal bleeding, ${ }^{2,17,19-25}$ although others have questioned the clinical importance of colonisation by spirochaetes. ${ }^{18,26}$ Interpretation of some of these observations may have been confused by the occurrence of a non-pathogenic spirochaete, Brachyspira aalborgi, which, although shorter than most of the spirochaetes described in this paper, also attaches to the lumenal surface of colonic enterocytes. ${ }^{26,27}$

The purpose of the present work was to characterise genetically intestinal spirochaetes from man that have been used in previously published studies, and that have been isolated from different populations, and to compare them with isolates from pigs. Multilocus 
enzyme electrophoresis was selected for the purpose of this analysis as it is readily applicable to studies of bacterial populations, ${ }^{28}$ and we have used this method previously to characterise intestinal spirochaetes. ${ }^{11,12,29}$ Specific aims of the project were to determine the relatedness of isolates from the different sources and to look for possible epidemiological links between them. The study expands previous work, ${ }^{12}$ in using additional spirochaetal isolates from new sources, including the type strain of Brachyspira aalborgi $i^{27}$ and a human spirochaete tentatively called "Serpulina jonesii". An abstract of preliminary results from part of this work has been published. ${ }^{30}$

\section{Materials and methods}

\section{Spirochaetes}

A total of 175 strains of anaerobic spirochaetes was analysed; 72 were of human origin and came from various sources. Forty-nine isolates were from Western Australian Aboriginal children living in a remote area, most of whom had some form of diarrhoea. ${ }^{2}$ Seven isolates were from Italian adults suffering from various intestinal disorders ${ }^{25}$ and were provided by Professor A. Sanna, Catholic University, Rome. Nine isolates were from the faeces of homosexual males in Sydney, Australia, all of whom had diarrhoea, ${ }^{31}$ and were provided by Dr S. Shanker, Westmead Hospital, Sydney. Four isolates were from Omani Arabs, ${ }^{1}$ and one was of uncertain origin; these isolates were provided by Dr S. P. Barrett, St Mary's Hospital, London. The final strains of human origin-obtained from the American Type Culture Collection under accession numbers 43994 and 49776, respectivelywere the type strain of Brachyspira aalborgi ${ }^{27}$ and a strain of the proposed new species "Serpulina jonesii". The latter strain was isolated originally in California from the faeces of a homosexual male with diarrhoea. ${ }^{6}$ Results of the analysis of 29 of the Aboriginal isolates and six of the Italian isolates have been published elsewhere. ${ }^{12}$ Details of the human isolates are presented in table I.

A total of 102 porcine isolates, all but three of which have been analysed previously, ${ }^{11,29}$ were included in the study for comparative purposes. These bacteria consisted of 20 isolates of $S$. hyodysenteriae from six electrophoretic types (ETs 1, 3, 9, 13, 15 and 16 in the study of Lee et $a l^{29}$ ), and 79 weakly $\beta$-haemolytic spirochaetes from a subsequent study. ${ }^{11}$ The latter included six isolates of " $S$. intermedius" (ETs 30-35), six isolates of $S$. innocens (ETs 38, 42-46), 11 isolates of the "group B spirochaetes" (ETs 51-56) and all 56 isolates (ETs 57-85) making up genetic group C ("Anguillina coli") in that study. ${ }^{11}$ The three additional porcine spirochaetes were isolated from the faeces of three pigs suffering from a dysentery syndrome in a Californian herd. These were provided by $\mathrm{Dr} R$. Walker, University of California, Davis, CA, USA. An isolate cultured from the faeces of a dog with diarrhoea was also analysed. This animal lived in the same community as the Australian Aboriginal children studied and was sampled at the same time as some of the children. ${ }^{2}$

Morphological and biochemical characteristics of most of the human intestinal spirochaetes that were used have been published elsewhere. ${ }^{2,6,12,25,27,31}$ All these that were examined by transmission electronmicroscopy, including the canine and three new porcine isolates, had four-to-six axial flagella inserted subterminally. Details of the other porcine isolates have been described elsewhere ${ }^{11,29}$ but, in summary, all those in the proposed genus "Anguillina" had four-tosix axial flagella, whereas those in the genus Serupulina had seven or more axial flagella.

\section{Microbial culture and enzyme extraction}

The spirochaetes were grown initially on trypticase soy agar supplemented with defibrinated ovine blood $5 \%$, spectinomycin $400 \mu \mathrm{g} / \mathrm{ml}$, and colistin and vancomycin, $25 \mu \mathrm{g} / \mathrm{ml}$ each at $37^{\circ} \mathrm{C}$ in an atmosphere of $\mathrm{H}_{2}, 94 \%, \mathrm{CO}_{2} 6 \%$. After incubation for a minimum of 5 days, colonies were subcultured into the trypticase soy broth-based pre-reduced anaerobic autoclaved liquid medium of Kunkle et al., ${ }^{34}$ supplemented with fetal calf serum $2 \%$ and a cholesterol $1 \%$ in ethanol solution. Broths were incubated at $37^{\circ} \mathrm{C}$ on a rocking platform and adequate growth and absence of contamination were monitored by examining samples by phase-contrast microscopy. Spirochaetes were pelleted from $350 \mathrm{ml}$ of broth when they were in late log-phase, usually after $72-96 \mathrm{~h}$, by centrifugation at $15000 \mathrm{~g}$ for $20 \mathrm{~min}$ at $4^{\circ} \mathrm{C}$. The pellets were then washed twice in

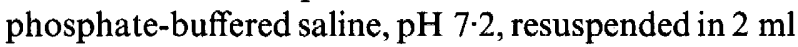
of sterile double-distilled water, lysed by three 30 -s cycles of sonication and cooled on ice. After centrifugation at $20000 \mathrm{~g}$ for $20 \mathrm{~min}$ at $4^{\circ} \mathrm{C}$, the supernates were dispensed in $150-\mu 1$ volumes and stored at $-70^{\circ} \mathrm{C}$ until used.

\section{Multilocus enzyme electrophoresis}

The supernates were subjected to electrophoresis in horizontal starch $11.4 \%$ gels and the electrophoretic mobilities of 15 constitutive enzymes were examined. Details of enzymes, buffers and electrophoretic conditions used have been published elsewhere. ${ }^{11,12,28,29}$ The enzymes are listed in table II.

\section{Analysis}

Genetic diversity for each enzyme locus was calculated as follows :

$$
h=\left(1-\Sigma p_{i}^{2}\right)(n / n-1)
$$

where $p_{1}$ is the frequency of the $i$ th allele among ETs and $n$ is the number of ETs. ${ }^{35}$ Total genetic diversity 
(H) was calculated as the mean of $h$ over all loci. Genetic distance between pairs of ETs was calculated as the proportion of fixed loci at which dissimilar alleles occurred, with a computer clustering program (Phentree) based on the Taxan 2 package. The program was used to create a phenogram by the unweighted pair-group method of arithmetic averages (UPGMA) clustering fusion strategy.

\section{Results}

\section{Porcine isolates}

The 99 porcine isolates (described in previous studies) were divided into two major genetic groups, as shown in the figure. The first group contained all the isolates of $S$. hyodysenteriae (ETs 1-6), " $S$. inter-

Genetic Distance

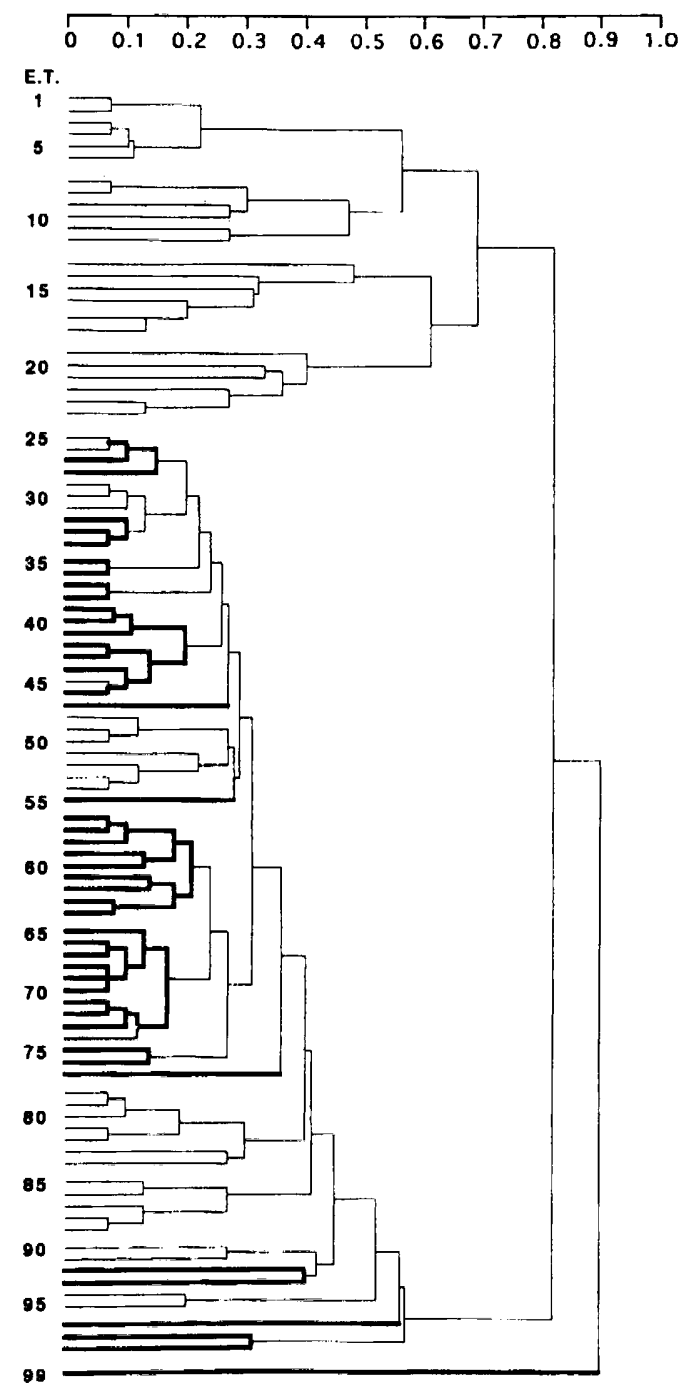

Figure. Phenogram of genetic distance (expressed as percentage fixed allelic differences) amongst ETs of 72 human, one canine and 102 porcine intestinal spirochaetes, clustered by the UPGMA strategy. Human isolates were located in the 45 ETs outlined in bold. The location of the canine isolate (ET 74) is shown by a hatched line. Isolates in ETs 1-24 belong to the genus Serpulina, those in ETs 25-98 to the proposed genus "Anguillina", and that in ET 99 to the genus Brachyspira. medius" (ETs 7-12), S. innocens (ETs 13-18) and the "group B spirochaetes" (ETs 19-24). The group B spirochaetes were separated from $S$. innocens at a genetic distance of 0.61 and both were separated from the other two species of Serpulina at a distance of 0.69 . The spirochaetes in this first group were all separated at a genetic distance of 0.82 from the 59 porcine spirochaetes in the second group (ETs 25-98 in the figure). The latter porcine spirochaetes have been assigned previously to a proposed new genus "Anguillina"." The three previously untyped porcine isolates were all located in this second group, in ET 30, together with porcine strain P43/6/78. Within this group, most porcine isolates were distinct from the human isolates (see below). However, there were three clusters of porcine isolates, members of which showed allelic differences from each other at two or less loci, which also included isolates of human origin. These clusters of isolates were in ETs 25-27, 29-34 and $44-46$, respectively (figure).

\section{Canine isolate}

The canine isolate was located by itself in ET 74. It differed at three alleles from its most closely related neighbour in ET 73, which was isolated from an Aboriginal child living in the same community as the dog.

\section{Human isolates}

B. aalborgi ATCC 43994 was located in ET 99, separated from all other spirochaetes at a genetic distance of 0.90 . The other 71 human isolates were distributed into 44 ETs (table I), all with the proposed genus "Anguillina" (ETs 25-98 in the figure). Allelic frequencies and genetic diversity amongst these 44 ETs are presented in table II; overall diversity was 0.32 . For these isolates only the enzymes nucleoside phosphorylase (NP) and superoxide dismutase (SOD) were monomorphic. The mean number of alleles/locus was 3.13. The 71 isolates were divided into 26 "clonal groups", defined here as groups of isolates that differed at two or less alleles over the 15 loci (table III). Three of these clonal groups ("clones") contained porcine isolates (see above). The mean number of human isolates per clone was $2 \cdot 73$, with a range of $1-16$ isolates. Only four of the clones contained human isolates from more than one source: one clone contained isolates from Italian adults and Western Australian Aboriginal children (ETs 32-34), and three contained isolates from homosexual males in Sydney and from Western Australian Aboriginal children (ETs 39-41, 56-58 and 71-73 respectively) (table III). The isolate of "S. jonesii" was located in ET 93, in the genus "Anguillina". It was separated from the most closely related human isolate (ET 92) at a genetic distance of 0.40 . 
Table I. Electrophoretic type (ET) and origin of human intestinal spirochetes

\begin{tabular}{|c|c|c|c|c|}
\hline $\begin{array}{l}\text { ET } \\
\text { no. }\end{array}$ & Strain or isolate designation & Origin & Patient & $\begin{array}{c}\text { Reference } \\
\text { no. }\end{array}$ \\
\hline 27 & HRM 5 & Italy & $A ; d$ & 25,32 \\
\hline 28 & H 54-2 & WA & $\mathrm{C} ; \mathrm{d}$ & 2 \\
\hline 32 & HRM 2 & Italy & $A ; d$ & 25,32 \\
\hline 33 & HRM 7 & Italy & $\mathrm{A} ; \mathrm{t}$ & 25,32 \\
\hline 34 & $\mathrm{H} 38 ; \mathrm{H} 4$ & WA & $\mathrm{C} ; \mathrm{d}$ & 2 \\
\hline 35 & Mar & WA & $\mathrm{C} ; \mathrm{d}$ & 2 \\
\hline 36 & Kar; Barn & WA & $C ; d$ & 2 \\
\hline 37 & 13 & Oman & $C ; d$ & 1 \\
\hline 38 & 14 & Oman & A;gd & 1 \\
\hline 39 & HRM 1 & Italy & A; gd & 25,32 \\
\hline 40 & GAP 183 & Sydney & $\mathrm{AH} ; \mathrm{d}$ & 31 \\
\hline 41 & HRM 8 & Italy & $\mathrm{A} ; \mathrm{gd}$ & 25,32 \\
\hline 42 & Que; DisA; WesA; Mel; Vri; Kid; Lev; Tum; Sta; Sha & WA & $\mathrm{C} ; \mathrm{d}$ & 2 \\
\hline 43 & Marg A; Marg B; Mat A; Mat B; Mars; Cis & WA & $\mathrm{C} ; \mathrm{d}$ & 2 \\
\hline 44 & H 44 & WA & $\mathrm{C} ; \mathrm{d}$ & 2 \\
\hline 46 & 700 & WA & $\mathrm{C} ; \mathrm{d}$ & 2 \\
\hline 47 & 31 & Oman & $\mathrm{C} ; \mathrm{d}$ & 1 \\
\hline 55 & HRM 14 & Italy & A; na & 25,32 \\
\hline 56 & GAP 51-2 & Sydney & $\mathrm{AH} ; \mathrm{d}$ & 31 \\
\hline \multirow[t]{2}{*}{57} & GAP 37 & Sydney & $\mathrm{AH} ; \mathrm{d}$ & 31 \\
\hline & 167 & WA & $\mathrm{C} ; \mathrm{d}$ & 2 \\
\hline 58 & GAP 34-2 & Sydney & $\mathrm{AH} ; \mathrm{d}$ & 31 \\
\hline 59 & Raq & WA & $\mathrm{C} ; \mathrm{d}$ & 2 \\
\hline 60 & Roch; Son & WA & $\mathrm{C} ; \mathrm{d}$ & 2 \\
\hline 61 & HRM 4 & Italy & A; gd & 25,32 \\
\hline 62 & Tris & WA & $\mathrm{C} ; \mathrm{d}$ & 2 \\
\hline 63 & GAP 418 & Sydney & $\mathrm{AH} ; \mathrm{d}$ & 31 \\
\hline 64 & GAP 51-1 & Sydney & $\mathrm{AH} ; \mathrm{d}$ & 31 \\
\hline 65 & H $39-2$ & WA & $C ; d$ & 2 \\
\hline 66 & Wes B; Vir A; Joy; Let; Ama & WA & $\mathrm{C} ; \mathrm{d}$ & 2 \\
\hline 67 & Nao & WA & $\mathrm{C} ; \mathrm{d}$ & 2 \\
\hline 68 & H $62 ; \mathrm{H} 43$ & WA & $\mathrm{C} ; \mathrm{d}$ & 2 \\
\hline 69 & H $7-2$ & WA & $\mathrm{C} ; \mathrm{d}$ & 2 \\
\hline 70 & H 56-2 & WA & $C ; d$ & 2 \\
\hline \multirow[t]{2}{*}{71} & GAP 401 & Sydney & $\mathrm{AH} ; \mathrm{d}$ & 31 \\
\hline & H $60-2 ;$ H 21 & WA & $\mathrm{C} ; \mathrm{d}$ & 2 \\
\hline 72 & GAP 417 & Sydney & $\mathrm{AH} ; \mathrm{d}$ & 31 \\
\hline 73 & H $61-2$ & WA & $\mathrm{C} ; \mathrm{d}$ & 2 \\
\hline 75 & Cha; Rus; Cut & WA & $\mathrm{C} ; \mathrm{d}$ & 2 \\
\hline 76 & ED & WA & $\mathrm{C} ; \mathrm{d}$ & 2 \\
\hline 77 & Jer A & WA & $C ; d$ & 2 \\
\hline 92 & FT 6 & UK & $\mathrm{AH} ; \mathrm{d}$ & - \\
\hline 93 & "Serpulina jonesii" & USA & $\mathrm{AH} ; \mathrm{d}$ & 6 \\
\hline 96 & Shan & WA & $\mathrm{C} ; \mathrm{d}$ & 2 \\
\hline 97 & GAP 219 & Sydney & $\mathrm{AH} ; \mathrm{d}$ & 33 \\
\hline 98 & 11 & Oman & A;gd & 1 \\
\hline 99 & Brachyspira aalborgi & Denmark & $A ; h$ & 27 \\
\hline
\end{tabular}

WA, Western Australian Aboriginal samples; A, adult; AH, adult homosexual male; C, child; d, diarrhoea $\mathrm{h}$, healthy; $\mathrm{t}$, tumour; gd, gastrointestinal disturbance; na, not available.

\section{Discussion}

Multilocus enzyme electrophoresis was used to separate the 175 spirochaetes into 99 ETs. These ETs were divided into three major genetic groupings, made up of ETs 1-24, 25-98 and 99 respectively. We consider that the groupings are likely to represent the three genera: Serpulina, "Anguillina" and Brachyspira, respectively. "Anguillina" is not currently an approved name, and 16S ribosomal RNA sequence analysis will be required before it can be validated.

The first group contained strains, including the type strains, from two accepted species of Serpulina. These were $S$. hyodysenteriae (ETs 1-6), and $S$. innocens (ETs 13-18). Another proposed species, "S. intermedius", ${ }^{11}$ in ETs 7-12, made up part of the group, and in this study was more closely related to $S$. hyodysenteriae than to $S$. innocens. As previously demonstrated, members of this new "species" also have certain biochemical reactivities which are intermediate between those characteristically possessed only by $S$. hyodysenteriae or $S$. innocens, ${ }^{11}$ but like both species they possess 7-14 axial flagella. In our previous study ${ }^{11}$ a group of spirochaetes was also identified that closely resembled $S$. innocens phenotypically, but they were genetically distinct. We called these the "group B spirochaetes". They differed phenotypically from typical $S$. innocens isolates only in that they lacked $\alpha$ galactosidase activity. In the current study, with a subset of isolates from our previous study, ${ }^{11}$ the group B spirochaetes were contained within ETs 19-24, within the first group of ETs in the phenogram. They 
Table II. Allelic frequencies and genetic diversities at 15 enzyme loci amongst 44 ETs of human intestinal spirochaetes of the proposed genus " Anguillina"

\begin{tabular}{|c|c|c|c|c|c|c|c|}
\hline \multirow{2}{*}{$\begin{array}{l}\text { Enzyme } \\
\text { locus }\end{array}$} & \multicolumn{6}{|c|}{ Frequency of allele no. } & \multirow{2}{*}{$\begin{array}{c}\text { Genetic } \\
\text { diversity* }\end{array}$} \\
\hline & 1 & 2 & 3 & 4 & 5 & 6 & \\
\hline GDA & 0.05 & 0.02 & 0.13 & 0.30 & 0.34 & 0.07 & 0.75 \\
\hline $\mathrm{AK}$ & 0.09 & 0.39 & $0 \cdot 11$ & 0.39 & & & 0.66 \\
\hline FDP & 0.09 & 0.43 & 0.48 & & & & 0.56 \\
\hline GDH & 0.52 & 0.46 & 0.02 & & & & 0.51 \\
\hline PEP & 0.02 & 0.57 & 0.41 & & & & 0.50 \\
\hline EST & 0.02 & 0.07 & 0.70 & 0.21 & & & 0.45 \\
\hline HK & 0.79 & 0.07 & 0.05 & & & & 0.34 \\
\hline MI & 0.02 & 0.81 & 0.07 & 0.05 & 0.05 & & 0.31 \\
\hline $\mathrm{ACP}$ & 0.05 & 0.88 & 0.05 & & & & 0.20 \\
\hline ALP & 0.91 & 0.07 & 0.02 & & & & $0 \cdot 16$ \\
\hline GPI & 0.09 & 0.91 & & & & & 0.16 \\
\hline PGM & 0.94 & 0.04 & 0.02 & & & & 0.13 \\
\hline $\mathrm{ADH}$ & 0.93 & 0.07 & & & & & 0.13 \\
\hline NP & 1.00 & & & & & & 0 \\
\hline SOD & 1.00 & & & & & & 0 \\
\hline
\end{tabular}

GDA, guanine deaminase; AK, adenylate kinase; FDP, fructose-16-diphosphatase; GDH, glutamate dehydrogenase: PEP, L-leucylglycl-glycine peptidase; EST, esterase; HK, hexokinase; MPI, mannose phosphate isomerase; ACP, acid phosphatase; ALP, alkaline phosphatase; GPI, glucose phosphate isomerase; PGM, phosphoglucomutase; ADH, alcohol dehydrogenase; NP, nucleoside phosphorylase; SOD, superoxide dismutase.

*Mean genetic diversity, $0 \cdot 32$.

Table III. Clonal groupings of human intestinal spirochaetes of the proposed genus "Anguillina"

\begin{tabular}{|c|c|c|c|}
\hline & $\begin{array}{c}\text { Clonal } \\
\text { groupings* }\end{array}$ & $\begin{array}{l}\text { Number of } \\
\text { isolates }\end{array}$ & Origin (number) \\
\hline \multirow[t]{26}{*}{ ET } & $27 \dagger$ & 1 & I \\
\hline & 28 & 1 & WA \\
\hline & $32-34 \dagger$ & 4 & $\mathrm{I}(2) ; \mathrm{WA}(2)$ \\
\hline & $35-36$ & 3 & WA \\
\hline & 37,38 & 2 & $\mathrm{O}$ \\
\hline & $39-41$ & 3 & $\mathrm{WA}(2) ; \mathrm{S}(1)$ \\
\hline & 42,43 & 16 & WA \\
\hline & $44,46+$ & 2 & WA \\
\hline & 47 & 1 & $\mathrm{O}$ \\
\hline & 55 & 1 & I \\
\hline & $56-58$ & 4 & $\mathrm{WA}(1) ; \mathbf{S}(1)$ \\
\hline & 59,60 & 3 & WA \\
\hline & 61 & 1 & I \\
\hline & 62 & 1 & WA \\
\hline & 63,64 & 2 & $\mathrm{~S}$ \\
\hline & 65 & 1 & WA \\
\hline & $66-70$ & 10 & WA \\
\hline & $71-73$ & 4 & $\mathrm{WA}(2) ; \mathrm{S}(2)$ \\
\hline & 75 & 3 & WA \\
\hline & 76 & 1 & WA \\
\hline & 77 & 1 & WA \\
\hline & 92 & 1 & $\mathrm{~L}$ \\
\hline & 93 & 1 & Call \\
\hline & 96 & 1 & WA \\
\hline & 97 & 1 & $\mathrm{~S}$ \\
\hline & 98 & 1 & $\mathrm{O}$ \\
\hline
\end{tabular}

I, Italy; WA, Western Australia; S, Sydney; O, Oman; L, London; Cal, California.

* Isolates with allelic difference at $\leqslant 2$ of 15 enzyme loci.

$\dagger$ Part of a clonal grouping that included porcine spirochaetes.

were separated from $S$. innocens only at a genetic distance of 0.61 , compared to 0.74 in our previous study. ${ }^{11}$ On the basis of the current results, and the preliminary results of DNA hybridisation experiments (A. J. McLaren and D. J. Hampson, unpublished data), we suggest that the group B spirochaetes are a new species of Serpulina (for which we propose the name "Serpulina murdochii", after our University). This needs to be verified by additional techniques so that a fuller description of the new species can be published. In summary, we propose that the first group of the phenogram corresponds to the genus Serpulina, containing four species $S$. hyodysenteriae, " $S$. intermedius", $S$. innocens and " $S$. murdochii" respectively.

The second main genetic group on the phenogram (ETs 25-98) contained all but one of the isolates from human beings, the canine isolate, and all the porcine isolates of the proposed new genus " Anguillina" in our previous study. ${ }^{11}$ This group was separated at a genetic distance of 0.82 from the spirochaetes in the genus Serpulina. The spirochaetes in this group were also distinct in having only four-to-six axial flagella. We consider that all these isolates belong to the new genus "Anguillina". Furthermore, because of the presence of some more distantly related isolates in the group, it is likely to comprise more than the single species, " $A$. coli", that we described previously. ${ }^{11}$

The third genetic group (ET 99) contained the type strain of $B$. aalborgi, which was obtained from the ATCC. It was quite distinct from both previous groups, being separated from them at a genetic distance of 0.90 . This was consistent with it being a member of a separate genus. ${ }^{27}$ This finding was of considerable importance, since some previous descriptions of "intestinal spirochaetosis" have been related to colonisation with this distinct bacterium. ${ }^{26}$ The conclusion drawn from these studies, that colonisation with intestinal spirochaetes has no clinical significance, ${ }^{26}$ clearly does not necessarily apply to colonisation with other types of spirochaete.

The three porcine isolates that we had not analysed previously belonged to ET 30, together with strain $\mathrm{P} 43 / 6 / 78$. The latter strain was the original Scottish isolate from the first recorded case of porcine intestinal spirochaetosis $;^{13}$ the three new isolates were from different pigs suffering from a dysentery syndrome in a Californian herd. These findings indicate that this clone of spirochaetes is widespread, and is likely to be pathogenic to pigs. Closely-related strains also infect humans (see below).

The canine isolate belonged to ET 74, also in the new genus "Anguillina". Dogs are known to be colonised commonly by various morphological forms of intestinal spirochaete. ${ }^{36}$ The bacteria are found more commonly and are more abundant in the faeces of dogs with diarrhoea than in the faeces of healthy dogs. ${ }^{37}$ Although this suggests that the spirochaetes may cause diarrhoea, it has also been shown that diarrhoea may flush spirochaetes from the crypts of normal animals, so that they appear in the faeces. ${ }^{38}$ Therefore, their presence may be only the result of diarrhoea, and not the cause of the condition. 
The morphology of the spirochaete analysed in the present study was similar to that described for spirochaetes isolated from two normal dogs in another study. ${ }^{33}$ These bacteria had six axial flagella. In our experience this type is not the typical sort of spirochaete found in dogs, since 26 other canine isolates that we have cultivated have been morphologically and genetically typical of bacteria in the genus Serpulina (J. I. Lee and D. J. Hampson, unpublished data).

The canine spirochaete in this study was closely related genetically to spirochaetes recovered from Aboriginal children with whom the dog lived. Both the children and the dog were suffering from diarrhoea. Koopman et al. ${ }^{39}$ also found close similarities between spirochaetes isolated from man and dogs, and our results support their suggestion that spirochaetes may be transmitted between human beings and dogs. Therefore, dogs should be considered as a possible reservoir of spirochaetal infection for man.

The 71 isolates from man, other than B. aalborgi, all belonged to the proposed genus "Anguillina" (ETs 25-98). This finding is consistent with our previous observations with smaller numbers of isolates, ${ }^{12,30}$ but differs from the results of an earlier study by Coene et $a .^{32}$ In that study, DNA homology values were obtained between certain human and porcine isolates, and it was concluded that the human isolates were closely related to the porcine isolates in the genus Serpulina. Subsequently, we used both multilocus enzyme electrophoresis analysis and DNA hybridisation experiments with some of their isolates and refuted those results. ${ }^{12}$

The bacteria belonging to the genus "Anguillina" were relatively diverse, with 26 clones of human spirochaetes being recognised. Of these clones, those represented by single isolates-in ETs 92, 93, 96, 97 and 98-were relatively distantly related to each other and to the other 66 human isolates in the genus. These five clones consisted of isolates from London, California, Western Australia, Sydney and Oman. The socalled "Serpulina jonesii", in ET 93, whilst clearly not a Serpulina, could be a representative of a separate species in the genus "Anguillina" ("Anguillina jonesii" may prove to be an appropriate name). Further work is required to confirm the taxonomic position of this isolate.

Generally, the porcine isolates were distinct from those of human origin, although three of the 26 clones of human isolates also contained porcine isolates. These were in ET clusters 25-27, 29-34 and 44-46, respectively. The first cluster included three Australian porcine isolates and human isolate HRM5 from Italy. The second included 14 porcine isolates, human isolates HRM2 and HRM7 from Italy, and H4 and H38 from Aboriginal children. This cluster included the porcine pathogenic spirochaete P43/6/78, in ET 30 (see above). Therefore, this clonal group is widely disseminated, and may colonise both man and pigs. In view of its association with dysentery syndromes in pigs ${ }^{13}$ the pathogenic potential for man of isolates in this clone also requires further investigation. The third of the clones containing both human and porcine isolates was made up of porcine isolate $\mathrm{M} 1$, which was received from Professor A. Sanna in Italy, and isolates H44 and 700 which were from Aboriginal children.

The number of human isolates in the 26 clones ranged from 1 ( 14 clones) to 16 isolates, with a mean of $2 \cdot 73$. Sixteen of the clones contained isolates from Western Australian Aboriginal children, including the two largest clones made up of 10 and 16 isolates, respectively. The greater number of clones from this source, which also tended to contain more isolates than clones from other sources, probably resulted from the large number of Aboriginal isolates that were examined. Furthermore, there was ample opportunity for frequent transmission of specific spirochaetal strains between children in the Aboriginal communities. $^{2}$

Four of the clones infected individuals from different locations. All four of these contained isolates from Aboriginal children; one also contained two isolates from Italian adults and three contained isolates recovered from homosexual men in Sydney. There were no known connections between the extremely remote Aboriginal communities and the other sources.

The role of intestinal spirochaetes of the genus "Anguillina" as initiators or exacerbators of diarrhoea in man requires further investigation. They should not be confused with the small spirochaete $B$. aalborgi, which attaches to colonic epithelium, but does not cause disease. ${ }^{26}$ Certainly it is evident that different human populations and animal species can harbour very similar strains of "Anguillina spp.", and in this study most of the individuals from whom the bacteria were recovered were suffering from diarrhoea or other gastrointestinal disorders. However, this does not prove conclusively a causal relationship. To do this convincingly it will be necessary to fulfil Koch's postulates by developing and using appropriate animal models of the infection in man.

This work was supported by grants from the Australian Pig Research and Development Corporation and from Murdoch University. J. I. L. was in receipt of an Australian Vice-Chancellors' Postgraduate Scholarship. We thank S. P. Barrett, G. L. Gilbert, C. Law, A. Sanna, S. Shanker and R. Walker for their generosity in providing various intestinal spirochaetes for use in the study. D. J. Trott and C. D. Maltas provided technical assistance.

\section{References}

1. Barrett SP. Intestinal spirochaetes in a Gulf Arab population. Epidemiol Infect 1990; 104: 261-266.

2. Lee JI, Hampson DJ. Intestinal spirochaetes colonizing Abor- igines from communities in the remote north of Western Australia. Epidemiol Infect 1992; 109: 133-141.

3. Macfie JWS. The prevalence of Spirochaeta eurygyrata in Europeans and natives in the Gold Coast. Lancet 1917; 1 : $336-340$. 
4. Mathan MM, Mathan VI. Rectal mucosal morphologic abnormalities in normal subjects in Southern India: a tropical colonopathy? Gut 1985; 26: 710-717.

5. Kasbohrer A, Glederblom HR, Arasteh $\mathbf{K}$ et al. Intestinale spirochatose bei HIV Infektion. Vorkommen, Isolierung und Morphologie der Spirochaten. Dtsch Med Wochenschr 1990; 115: 1499-1506.

6. Jones MJ, Miller JN, George WL. Microbiological and biochemical characterization of spirochetes isolated from the feces of homosexual males. J Clin Microbiol 1986; 24 : 1071-1074.

7. Ruane PJ, Nakata MM, Reinhardt JF, George WL. Spirochete-like organisms in the human gastrointestinal tract. Rev Infect Dis 1989; 11: 184-196.

8. Tompkins DS, Waugh MA, Cooke EM. Isolation of intestinal spirochaetes from homosexuals. J Clin Pathol 1981; 34 1385-1387.

9. Tompkins DS, Foulkes SJ, Godwin PGR, West AP. Isolation and characterisation of intestinal spirochaetes. $J$ Clin Pathol 1986; 39: 535-541.

10. Jacques M, Girard C, Higgins R, Goyette G. Extensive colonization of the porcine colonic epithelium by a spirochete similar to Treponema innocens. J Clin Microbiol 1989; 27 : 1139-1141

11. Lee JI, Hampson DJ, Lymbery AJ, Harders SJ. The porcine intestinal spirochaetes: identification of new genetic groups. Vet Microbiol 1993; 34: 273-285.

12. Lee JI, McLaren AJ, Lymbery AJ, Hampson DJ. Human intestinal spirochaetes are distinct from Serpulina hyodysenteriae. J Clin Microbiol 1993; 31 : 16-21.

13. Taylor DJ, Simmons JR, Laird HM. Production of diarrhoea and dysentery in pigs by feeding pure cultures of a spirochaete differing from Treponema hyodysenteriae. Vet Rec 1980; 106: 326-332.

14. Harris DL, Glock RD, Christensen CR, Kinyon JM. Swine dysentery. I. Inoculation of pigs with Treponema hyodysenteriae (new species) and reproduction of the disease. Vet Med Small Anim Clin 1972; 67: 61-64.

15. Stanton TB. Proposal to change the genus designation Serpula to Serpulina gen nov containing the species Serpulina hyodysenteriae comb nov and Serpulina innocens comb nov. Int J Syst Bacteriol 1992; 42: 189-190.

16. Kinyon JM, Harris DL. Treponema innocens, a new species of intestinal bacteria, and emended description of the type strain of Treponema hyodysenteriae Harris et al. Int $J$ Syst Bacteriol 1979; 29: 102-109.

17. Harland WA, Lee FD. Intestinal spirochaetosis. BMJ 1967; 3: 718-719.

18. Lee FD, Kraszewski A, Gordon J, Howie JGR. McSeveney D, Harland WA. Intestinal spirochaetosis. Gut 1971; 12: 126-133.

19. Cotton DWK, Kirkham N, Hicks DA. Rectal spirochaetosis. Br J Vener Dis 1984; 60: 106-109.

20. Crucioli V, Busuttil A. Human intestinal spirochaetosis. Scand $J$ Gastroenterol 1981; 16 Suppl 70: 177-179.

21. Douglas JG, Crucioli V. Spirochaetosis: a remediable cause of diarrhoea and rectal bleeding? BMJ 1981; 283: 1362.
22. Gebbers JO, Ferguson DJP, Mason C, Kelly P, Jewell DP. Spirochaetosis of the human rectum associated with an intraepithelial mast cell and IgE plasma cell response. Gut 1987; 28 : 588-593.

23. Gad A, Willén R, Furugård K, Fors B, Hradsky M. Intestinal spirochaetosis as a cause of long standing diarrhoea. Ups $J$ Med Sci 1977; 82: 49-54.

24. Kaplan LR, Takeuchi A. Purulent rectal discharge associated with a nontreponemal spirochaete. JAMA 1979; 241: 52-53.

25. Sanna A, Dettori G, Agliano AM et al. Studies of treponemes isolated from human gastrointestinal tract. Ig Mod 1984; 81: 959-973.

26. Nielsen RH, Orholm M, Pedersen JO, Hovind-Hougen $\mathrm{K}$, Teglbjaerg PS, Thaysen EH. Colorectal spirochaetosis: clinical significance of the infestation. Gastroenterology $1983 ; 85: 62-67$

27. Hovind-Hougen $\mathrm{K}$, Birch-Andersen A, Henrik-Nielsen $\mathrm{R}$ et al. Intestinal spirochaetosis: morphological characterization and cultivation of the spirochaete Brachyspira aalborgigen. nov. sp. nov. J Clin Microbiol 1982; 16: 1127-1136.

28. Selander RK, Caugant DA, Ochman H, Musser JM, Gilmour MN, Whittam TS. Methods of multilocus enzyme electrophoresis for bacterial population genetics and systematics. Appl Environ Microbiol 1986; 51: 873-884.

29. Lee JI, Hampson DJ, Combs BG, Lymbery AJ. Genetic relationships between isolates of Serpulina (Treponema) hyodysenteriae, and comparison of methods for their subspecific differentiation. Vet Microbiol 1993; 34: 35-46.

30. Lee JI, Hampson DJ. Clonal analysis of intestinal spirochaetes. J Med Microbiol 1993; 38 Suppl 1: abstract 284.

31. Trivett N, Mallon R, Shanker S et al. Enteric spirochaetes of unknown taxon. Aust Microbiol 1992; 13: A144.

32. Coene M, Agliano AM, Paques AT et al. Comparative analysis of the genomes of intestinal spirochetes of human and animal origin. Infect Immun 1989; 57: 138-145.

33. Turek JJ, Meyer RC. Studies on a canine intestinal spirochaete. 1. Its isolation, cultivation and ultrastructure. Can J Comp Med 1977 ; $41: 332-337$.

34. Kunkle RA, Harris DL, Kinyon JM. Autoclaved liquid medium for propagation of Treponema hyodysenteriae. $J$ Clin Microbiol 1986; 24 : 669-671.

35. Nei $M$. Estimation of average heterozygosity and genetic distance from a small number of individuals. Genetics 1978; 89: 583-590.

36. Pindak FF, Clapper WE, Sherrod JH. Incidence and distribution of spirochetes in the digestive tracts of dogs. $\mathrm{Am}$ $J$ Vet Res 1965; 26: 1391-1402.

37. Zymet CL. Canine spirochaetosis and its association with diarrhea. Vet Med 1969; 64: 883-887.

38. Leach WD, Lee A, Stubbs RP. Localization of bacteria in the gastrointestinal tract: a possible explanation of intestinal spirochaetosis. Infect Immun 1973; 7: 961-972.

39. Koopman MBH, Käsbohrer A, Beckmann G, van der ZeijstBAM, Kusters JG. Genetic similarity of intestinal spirochetes from humans and various animal species. $J$ Clin Microbiol 1993; 31 : 711-716. 